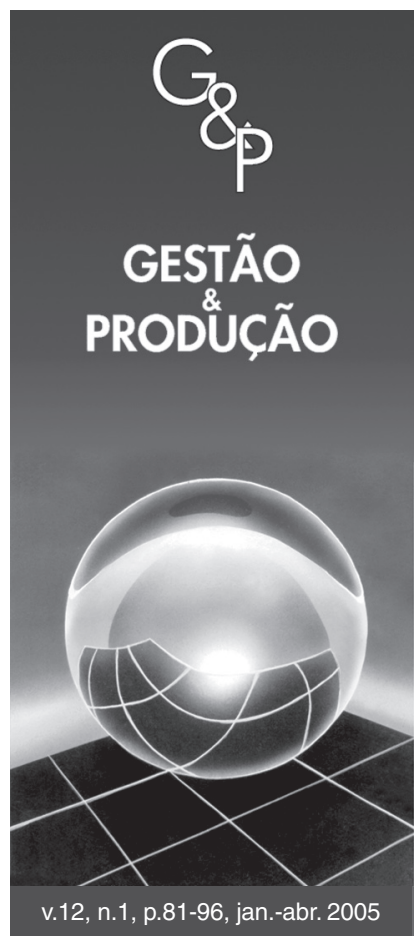

\title{
PROCESSOS DE PENSAMENTO DA TOC COMO ALTERNATIVA SISTÊMICA DE ANÁLISE ORGANIZACIONAL: UMA APLICAÇÃO EM SAÚDE PÚBLICA
}

Miguel Afonso Sellitto

Engenharia de Produção, Universidade do Vale do Rio dos Sinos, Unisinos, Av. Unisinos 950, CEP 93022-000, São Leopoldo, RS, e-mail: sellitto@euler.unisinos.br

Resumo

Recebido em 30/1/2004

Aceito em 11/1/2005

O objetivo deste trabalho é discutir o uso dos processos de pensamento da teoria das restrições, TOC (do inglês Theory of Constraints) como alternativa para análise sistêmica em organizações. Iniciou-se com uma revisão conceitual do pensamento sistêmico, uma referência a um dos vários métodos existentes na bibliografia e uma revisão dos processos de pensamento da TOC. A seguir foi apresentado um estudo de caso de uma aplicação do método da TOC conduzida em uma organização de saúde pública e uma discussão comparada entre o método da TOC e o método sistêmico referenciado. Ao final se conclui acerca da relação existente entre os métodos e situações sistêmicas de interesse, delimitando os tipos de situação em que cada método parece se comportar melhor e parece conduzir a resultados organizacionais aceitáveis.

Palavras-chave: pensamento sistêmico, teoria das restrições, processos de pensamento da teoria das restrições, planejamento de intervenções organizacionais.

\section{Introdução}

A partir do método de Descartes, surgido no século XVII, adotou-se na prática científica e na aprendizagem o princípio reducionista: a separação dos objetos de estudo em suas partes constituintes. Este princípio tem permeado a ciência e caracterizado a tradição intelectual do ocidente por 350 anos. No século XX o reducionismo foi significantemente desafiado, sendo seu maior desafiador o chamado movimento sistêmico, oriundo de três vertentes principais, a matemática, a computação e um conjunto de idéias expressas pelo termo pensamento sistêmico (system thinking) (Checkland e Scholes, 1998; Klir, 1991).

A atual formulação do pensamento sistêmico utiliza elementos da ciência dos sistemas e da teoria do controle realimentado. Esta formulação contrapõe o processo, o organismo, as inter-relações, as relações circulares e o dinâmico ao objeto, ao mecanismo, às partes, às relações unidirecionais e ao estático, característicos do reducionismo (Andrade e Kasper, 1997).

Andrade e Kasper (1997) sugerem algumas relações e identidades entre o pensamento sistêmico e áreas da engenharia de produção, dentre as quais a teoria das restrições. Proposta pelo doutor em física israelense Eliyahu Goldratt (1990), a teoria das restrições (theory of constraints - TOC) é centrada no conceito de restrição, o ente que limita os acréscimos que um sistema produtivo pode obter no resultado para o qual foi projetado.

A TOC inicia sua abordagem por métodos físicos, focalizadores de restrições materiais que, ao migrarem do campo das operações para o campo do gerenciamento, passam a exigir focalizadores de restrições intangíveis, os processos ou padrões de pensamento (thinking processes - TP). Os $T P$ foram introduzidos por Goldratt ao se aperceber que, devido à assunção de pressupostos errados, as restrições em operações passavam de físicas a lógicas, exigindo raciocínio abstrato, e não mais concreto, para a sua localização.

Entende-se que os processos de pensamento incorporam as bases do pensamento sistêmico, sendo uma alterna- 
tiva de análise sistêmica dos fenômenos organizacionais. O objetivo deste trabalho é discutir o uso dos processos de pensamento da TOC como alternativa para o planejamento de uma intervenção organizacional com base no pensamento sistêmico. O trabalho está estruturado em:

(i) revisão de métodos e conceitos sistêmicos;

(ii) referência ao método sistêmico descrito em Andrade (1997);

(iii) apresentação teórica e um caso de aplicação do método da $T O C$; e

(iv) análise comparada entre os métodos.

A aplicação tratou de uma situação de conflito na gestão de saúde pública em uma capital estadual brasileira.

\section{O método cartesiano}

Relacionar fenômenos observáveis na natureza com as suas causas não é novidade na história da ciência. $\mathrm{Na}$ Grécia antiga, filósofos já propunham a contemplação dos fenômenos como método de investigação dos seus mecanismos de governo, as relações de causalidade. Seu objetivo era encontrar uma explicação natural para fenômenos naturais: relacionar um efeito a uma causa que o antecede e o determina por meio de um nexo causal. A existência e o conhecimento do nexo causal tornariam a realidade inteligível (Souza Filho, 2000).

Na idade moderna, a escola racionalista propõe a investigação das causas dos fenômenos por meio da reflexão dedutiva. Dadas as premissas, pelo princípio absoluto do saber humano, a razão, se chega à conclusão. Renè Descartes (em latim Renatus Cartesius, origem do termo cartesiano) propõe a análise e a síntese: dividir o fenômeno nas partes necessárias para chegar a constituintes passíveis de entendimento e explicação racional e, opostamente, partir dos constituintes e voltar ao todo, identificando e relacionando as partes. A análise e a síntese operariam tanto em fenômenos naturais, dividindo e identificando constituintes físicos, como em fenômenos mentais, dividindo um conceito em conceitos subjacentes que o suportam e o reconstituem (Lakatos e Marconi, 1991).

Descartes identifica no intelecto humano duas faculdades: a intuição, pela qual se discerne clara, perfeita e irredutivelmente uma idéia, e a dedução, pela qual se encadeiam as idéias discernidas. O método cartesiano para a descoberta do saber emprega a intuição e a dedução, em quatro passos:

(i) a regra da evidência, pela qual não se exclui qualquer elemento a não ser que haja evidências que justifiquem a exclusão;

(ii) a regra da análise, que divide o objeto no maior número de partes possível para estudo, sem perder a organicidade; (iii) a regra da síntese, que reconstrói o conjunto separando as verdades independentes e absolutas das verdades derivadas, ordenadas conforme as relações existentes entre elas; e

(iv) regra da enumeração, que seleciona apenas os elementos necessários e suficientes para elaborar uma verdade sobre o objeto em estudo, sem omissões nem excessos (Descartes, 1996).

Verifica-se nas regras da síntese e da enumeração a preocupação cartesiana de não perder o foco no todo. Porém é verdadeiro que o uso do método cartesiano nas ciências administrativas distorceu a percepção em situações complexas. Ao se dividir um todo em suas partes constituintes, corre-se o risco de perder as relações que permeiam e interligam o sistema.

Uma expressão recorrente em textos de administração é: "o todo é maior do que a soma das partes". Acredita-se que, ao se seguir rigorosamente o método cartesiano, a expressão mais correta para as idéias subjacentes à expressão citada é: "a soma das partes é menor do que o todo" pois, ao fim da análise das partes, o método exige a síntese do todo.

\section{Pensamento sistêmico: suas bases de apoio e um método de análise organi- zacional}

O conceito de sistema começou a ser elaborado pelo biólogo Ludwig von Bertalanffy ao sugerir que suas idéias referentes a organismos como um todo poderiam ser aplicadas a outros tipos de todo (Checkland e Scholes, 1999). Da idéia de todo surge a definição de sistema: um conjunto de elementos interativos e relacionados entre si e com o meio-ambiente, que tem um objetivo, forma um todo e é caracterizado por suas partes e por suas interações. Sistemas podem ser classificados (i) pelo tipo de elementos; e (ii) pelo tipo de relações. A primeira classe remete às disciplinas da ciência e é essencialmente experimental, enquanto que a segunda classe remete à ciência dos sistemas, independe dos participantes e é essencialmente teórica. O estudo dos sistemas se vale das variáveis, objetos abstratos que têm um nome e podem ou não ter uma correspondência mensurável no mundo real. Outras definições relativas a sistemas são:

(i) objetivo: é a meta do sistema;

(ii) ambiente: são os cenários com que o sistema interage;

(iii) estruturas: são os sub-sistemas em que o sistema se divide;

(iv) elementos: são as unidades que compõem as estruturas;

(v) administração: é a lógica que regula as relações (Wiendahl, 1989); e

(vi) complexidade: é o número de variáveis, estados, 
partes, relações e interações ativas no sistema (Klir, 1991).

Quase todos os modos de organização humana podem ser explicados por sistemas, cuja modelagem admite certas regras (Wiendahl, 1989):

(i) um sistema possui elementos e ligações, que governam as relações entre os elementos;

(ii) um sistema é divisível em sub-sistemas de menor ordem;

(iii) conjuntos de elementos pertencentes a estruturas diferentes são sistemas parciais; e

(iv) todo elemento, sub-sistema ou sistema é delimitável por fronteiras que demarcam as entradas, saídas e funções.

Se não possuir entrada ou saída é dito um sistema fechado; do contrário é dito um sistema aberto.

Sistemas produtivos são abertos, pois interagem com forças externas em busca de um equilíbrio dinâmico. Se afetados por forças externas, usam forças internas para recompor o equilíbrio. Não se compreende, pois, uma parte de um sistema produtivo sem que se estudem suas relações com outras partes, suas interdependências, suas forças e suas cadeias prolongadoras de efeitos nos dois lados da fronteira organizacional (Wiendahl, 1989).

Para Andrade (1997), o pensamento sistêmico é um conjunto de princípios e ferramentas voltados para a análise da inter-relação das forças que atuam em um sistema e que têm comportamentos descritos pela teoria dos sistemas. O movimento destas forças pode ser entendido pela dinâmica dos sistemas, pois, algumas vezes, seus mecanismos agem de modo subjacente à estrutura formal, reagindo e se adaptando às modificações do meio-ambiente.

Acredita-se que ao menos dois campos de conhecimentos contribuíram para a atual formulação do pensamento sistêmico: a ciência dos sistemas e a teoria dos controles realimentados. Descrições compreensivas destes campos são apresentadas respectivamente em Klir (1991) e em Fregosi et al. (1980).

Ossimitz (1997) apresenta quatro diferentes enfoques para a ciência dos sistemas:

(i) a abordagem racionalista da matemática e da física, que descreve um sistema por equações diferenciais;

(ii) a teoria geral dos sistemas, iniciada por Bertalanffy (1977), que usa métodos matemáticos em $\mathbf{S}=(T, R)$, $T, R$ conjuntos de elementos em $\mathbf{S}$ e relações em $T$ (Klir, 1991, pág. 5);

(iii) a cibernética, iniciada por Wiener (1946, apud Jackson, 1993), que trata de mecanismos homeostáticos ou de auto-regulação, como a realimentação, e permitem que o sistema se transforme e sobreviva; e

(iv) a dinâmica de sistemas, iniciada por Forrester (1968), do MIT, nos anos 1960.
A dinâmica dos sistemas usa diagramas causais e diagramas de fluxo e armazenagem, apoiada por uma linguagem de simulação dinâmica que opera com variáveis de nível, os estoques, e de fluxo, as taxas. Se as equações diferenciais usam variáveis contínuas, a dinâmica de sistemas usa variáveis discretas: estoques são relacionados a um ponto no tempo, enquanto que taxas são relacionadas a intervalos de tempo (Forrester, 1968). Os diagramas sistêmicos podem representar relações físicas, como um sistema de distribuição de materiais, ou relações lógicas, como as reações de pessoas em situações organizacionais. Os mapas cognitivos, encontrados em Ensslin et al. (2001), também são úteis na construção de diagramas. Diagramas sistêmicos exigem algumas definições.

(i) elemento é o ente que representa uma situação;

(ii) precedência, quando um elemento surge antes de outro no tempo;

(iii) conseqüência, quando um elemento sucede outro no tempo;

(iv) conexões unem elementos a partir do precedente;

(v) enlace ou elo de realimentação: arranjo circular em que elementos são, ao mesmo tempo, precedência e consequiência, podendo ser reforçadores ou equilibradores, conforme a conseqüência reforçe ou atenue a precedência;

(vi) atrasos: quando as consequiências de um elemento só são percebidas um tempo depois de sua ocorrência; e

(vii) arquétipos: descrevem as situações já estudadas e são considerados em novas situações, pois alertam para efeitos possíveis, mas ainda não aparentes (Forrester, 1968; Goodman, 1996).

Os arquétipos são associáveis a comportamentos: variáveis não-limitadas sugerem arquétipos reforçadores, variáveis estáveis sugerem arquétipos equilibradores. Conforme o caso, a dinâmica de sistemas emprega a matemática (i) determinística, (ii) aleatória, as distribuições de probabilidade, (iii) das filas, os modelos markovianos, ou (iv) do domínio freqüência por meio das transformações de Laplace (Forrester, 1968; Klir, 1991).

O outro campo de conhecimentos afim é a teoria dos controles. Segundo Fregosi et al. (1980), foram desenvolvidos, em diferentes épocas, quatro enfoques teóricos:

(i) clássico, que trata com entradas, saídas e realimentações determinísticas;

(ii) analítico, que trata de amostrar e recompor sinais probabilísticos;

(ii) por variáveis de estado, que considera variáveis internas, as variáveis de estado; e

(iv) por álgebra abstrata, que trata com mecanismos de correlação entre entradas e saídas. 
Segundo os autores, textos mais recentes unificam os enfoques clássico e por variáveis de estado, o que é útil para este trabalho.

Pelo enfoque clássico:

(i) variáveis controladas ou de resposta são as variáveis finais, que se deseja comandar;

(ii) variáveis de controle são as variáveis que se consegue modificar e influenciar as variáveis de resposta; e

(iii) variáveis internas ou manipuladas controlam o fluxo da potência transformadora da sua fonte para a realidade, modificando a variável controlada.

O elo de realimentação faz uma amostragem da realidade por meio da variável de resposta que, ao ser comparada com a variável de controle, altera as variáveis internas. Se a realimentação e o controle tiverem polaridades opostas e a ação de controle for positiva, o elo de realimentação é negativo e equilibrador. Do contrário a realimentação é positiva e reforçadora (D’Azzo e Houpis, 1995).

O enfoque das variáveis de estado usa o conceito de estado de um sistema. Um sistema de ordem $n$ é descrito por $n$ equações diferenciais de primeira ordem com $n$ variáveis de estado. $\mathrm{O}$ valor das $n$ variáveis de estado em $t_{0}$ formam o vetor de estado $n$-dimensional em $t_{0}$. Um estado é a quantidade $n$-dimensional mínima de informação capaz de prever a saída em $t_{0}$ (Fregosi et al. 1980; Phillips e Harbor, 1997). Na Figura 1 se tem um sistema monomalha, em que o objetivo é a variável de controle, a variável manipulada é a variável interna e a amostra é a variável de resposta. Realidades mais complexas exigem sistemas multimalhas.

Diversos métodos de trabalho baseados nos fundamentos teóricos do pensamento sistêmico foram propostos por especialistas, dentre os quais se destacam os métodos apresentados em Forrester (1968), Checkland e Scholes (1998) e Pidd (1998). Estudos de caso são apresentados em Jackson (1993). Como referência será usado o método apresentado em Andrade (1997), que se vale do modelo dos diversos níveis de profundidade de percepção apresentado em Senge (1990):

(i) eventos físicos, tangíveis e mensuráveis;

(ii) padrões de comportamento no tempo que, a partir do comportamento passado, monitorado por gráficos

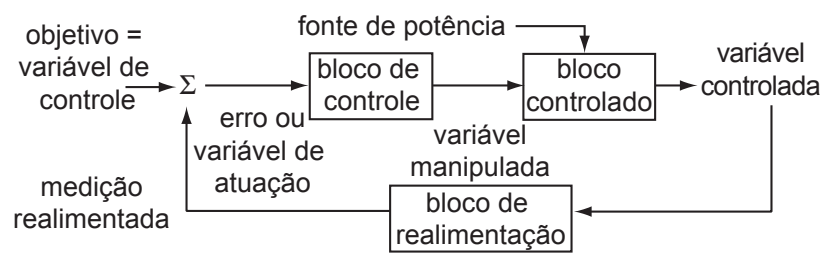

Figura 1. Sistema de controle elementar realimentado (fonte: D’Azzo e Houpis, 1995). de longo termo, lançam elementos para a previsão do comportamento futuro;

(iii) estruturação sistêmica da situação, que aponta os fatores que influenciam os padrões de comportamento e os eventos físicos; e

(iv) modelos mentais, que são os motivos, as crenças e os valores subjacentes à estrutura que a justificam e explicam os padrões comportamentais.

O objetivo de Andrade (1997) é localizar o ponto de alavancagem: ações que modifiquem a estrutura sistêmica e o comportamento das variáveis.

De modo geral, métodos de intervenção organizacional apresentam três blocos:

(i) fazer a leitura da situação atual;

(ii) diagnosticar o que contribuiu para gerar a situação atual; e

(iii) propor planos de trabalho para avançar a partir da situação atual.

O método de Andrade (1997) distribui estes três blocos nos dez passos apresentados na Tabela 1.

\section{Os processos de pensamento da TOC: histórico e antecedentes}

Goldratt entrou quase que casualmente na administração da produção quando criou uma técnica para resolver um problema específico de programação. A técnica foi formalizada em nove princípios, a OPT (Optimized Production Technology). Para divulgar a $O P T$ a praticantes, Goldratt escreveu a novela "A meta", contendo apenas a parte inicial do conhecimento já consolidado na prática. Mesmo assim, ao se aplicar esta parcela inicial, já se obtinha um salto na produtividade fabril. Na seqüência, porém, advinha um período de estagnação, pois a causa dos problemas saía da área industrial. Era preciso ensinar também o raciocínio lógico capaz de tratar os novos problemas. Goldratt formulou então a sua teoria das restrições, abrangendo e ampliando a OPT (Rodrigues, 1990; Goldratt, 1988).

A TOC trata restrições físicas com métodos físicos e restrições lógicas com os processos de raciocínio, os $T P$. $\mathrm{O}$ objetivo dos TP é oferecer uma abordagem sistêmica que explicite os nexos causais e explique as relações entre fenômenos observados em organizações. Goldratt iniciou a estruturação dos TP em 1990 na obra "What is this thing called the theory of constraints", não traduzida. Como a obra não foi resolutiva, Goldratt montou dois grupos de consultores experientes em restrições físicas para completarem a obra. Os dois tipos de $T P$, apoiados em cinco ferramentas objetivas de aplicação, atingiram sua forma atual em uma reunião final dos dois grupos na Holanda em agosto de 1991 (Scheinkopf, 1999; Noreen et al., 1996).

A $T O C$ propõe um método para gerenciar restrições: 
Tabela 1. Método sistêmico para planejamento de intervenções organizacionais (fonte: Andrade, 1997).

\begin{tabular}{cl}
\hline Passo & \multicolumn{1}{c}{ Atividade } \\
\hline 1 & Definir a situação complexa de interesse; \\
2 & Apresentar a história por meio de eventos e, com isto, prescrutar o nível mais externo do pensamento sistêmico; \\
3 & $\begin{array}{l}\text { Identificar os fatores-chave, ou seja, dentre os eventos levantados, aqueles que têm mais ligação e mais influência sobre a situ- } \\
\text { ação de interesse; }\end{array}$ \\
4 & Levantar o comportamento histórico e traçar gráficos das variáveis de interesse; \\
5 & $\begin{array}{l}\text { Baseado nas curvas, hipóteses, experimentos, intuições e conhecimentos, identificar as relações de influência e as relações } \\
\text { causais necessárias para construir a estrutura sistêmica da situação; }\end{array}$ \\
7 & Identificar os modelos mentais, apontando crenças e pressupostos que justificam as estruturas sistêmicas; \\
8 & Se possível, aplicar um arquétipo já conhecido e catalogado; \\
9 & Modelar em computador, com software simulador capaz de simular o comportamento dinâmico atual do sistema; e \\
10 & Tentar alternativas no simulador, identificando novas estruturas capazes de melhorar o resultado na situação de interesse. \\
\hline
\end{tabular}

(i) identificar a restrição do sistema;

(ii) decidir como explorar esta restrição;

(iii) subordinar tudo o mais à restrição: as não-restrições devem produzir no ritmo da restrição, pois, se produzirem mais, aumentarão custos sem aumentar o ganho;

(iv) ao não poder elevar mais o ganho elevar a restrição; e

(v) se a restrição foi rompida, voltar ao primeiro passo sem deixar que a inércia crie uma nova restrição: as antigas regras, não atualizadas, geram as novas restrições (Goldratt, 1990).

A $O P T$ passa a ser um caso particular da TOC, limitado à logística industrial. Sellitto (1999, pág. 40) deduz teoricamente o algoritmo TPC (tambor-pulmão-corda, a materialização da $O P T$ no chão-de-fábrica) pelos três primeiros passos do método.

Kendall (1998) classifica as restrições em (i) físicas: recursos incapazes de cumprir os requisitos de produção; e (ii) invisíveis: políticas, habilidades e medições necessárias em um momento, mas que, após mudanças, passaram a ser danosas ao resultado. Scheinkopf (1999) classifica as restrições em: (i) físicas: abordáveis pela $O P T$; (ii) políticas: regras que geram as restrições físicas; e (iii) paradigmáticas: as crenças que geram as restrições políticas.

Restrições políticas e paradigmáticas são abordadas pelo raciocínio abstrato dos $T P$.

O quinto passo do método de Goldratt explica como surgem estas restrições em um sistema produtivo.

A TOC exige três tipos de indicadores para a monito- ração de seus processos de melhorias (Goldratt, 1996):

(i) indicadores do resultado, que devem representar o propósito final do sistema;

(ii) indicadores de inventário, que devem representar o quanto o sistema precisa acumular para cumprir seu propósito; e

(iii) indicadores de despesas operacionais, que representam o quanto o sistema despende para cumprir seu propósito.

\subsection{Classificação, estrutura e simbologia dos processos de pensamento}

Os TP exploram a capacidade de adaptação e de aprendizado da organização ao procurar respostas para três questões:

(i) o que mudar;

(ii) para o que mudar; e

(iii) como mudar.

Os $T P$ são dois: a suficiência das causas, que enumera as precedências suficientes, e as condições necessárias, que enumeram os requisitos para que um ente exista (Scheinkopf, 1999).

A suficiência de causas se vale da causalidade. A causalidade é uma relação de conseqüência e precedência que pode envolver dois ou mais entes e ser verificada ao se explicitarem outros efeitos que surgiriam se o ente causador existisse. Se a existência destes efeitos secundários for verificada, a relação de causalidade é declarada 
válida. A causalidade de um ente efeito pode ser associada a mais do que um ente causa. Se apenas um dos dois entes causais é suficiente para gerar o efeito, tem-se uma lógica OU. Se o efeito exige que ambos os entes causais existam, tem-se uma lógica E. O padrão de suficiência de causa descreve as relações do tipo efeito-causa-efeito:

(i) se um ente existe, causa a existência de outro; ou

(ii) um ente, o efeito, é o resultado inevitável da existência de outro ente, a causa.

A validade da relação de causalidade é testada ao se responder por que a relação é válida, explicitando o nexo causal, o ente responsável pela relação de causalidade entre a causa e o efeito (Goldratt, 1990).

Os relacionamentos efeito-causa-efeito podem ser verificados com as ressalvas legítimas. As ressalvas legítimas são questionamentos opositores à relação que se tenta verificar e cujo sucesso no falseamento irá validar a relação. Scheinkopf (1999) sugere que uma relação de causalidade deve superar ao menos três tipos de ressalvas legítimas:

(i) verificação de que o que foi atestado realmente existe;

(ii) validação das relações entre causas e efeitos e verificação de suas suficiências; e

(iii) verificação de que os entes investigados realmente representam os propósitos da investigação e os comunicam a todos os interessados.

Já Kendall (1998) apresenta oito categorias de ressalvas legítimas:

(i) clareza na informação: exige ausência de erros na comunicação;

(ii) existência do ente: ao menos um teste de verificação deve ser realizado;

(iii) causalidade: um teste deve ser realizado;

(iv) insuficiência de causa: verifica se a causa apontada é suficiente para gerar o efeito verificado;

(v) causas adicionais: verifica se outros efeitos também são causas para o efeito apontado;

(vi) efeito previsível: verifica que outros efeitos secundários são gerados pela causa apontada;

(vii) inversão de relação: verifica se a causa e o efeito apontados não estão invertidos; e

(viii) tautologia: verifica se dois entes apenas coexistem, sem que haja uma relação de causalidade entre eles.

Os testes de validade devem incluir experimentos empíricos ou, ao menos, sessões de brainstorming para que o resultado das relações de causalidade seja conhecido e depurado e que surjam causas adicionais para todos os efeitos verificados (Scheinkopf, 1999).

O padrão de pensamento de causas necessárias surge quando se investigam os requisitos necessários para a existência de um fenômeno. Estas condições necessárias são as regras, as práticas ou os fenômenos que devem existir para que um dado efeito seja verificado. É possível que se assumam como válidas condições necessárias que não foram comprovadas empiricamente, surgindo limitações artificiais que não ocorreriam se as verdadeiras condições necessárias fossem conhecidas. Isto ocorre ao se inferirem como válidos pressupostos que não foram explicitados ou verificados. Uma condição necessária é verificada por ao menos um dos seguintes testes:

(i) para que exista [efeito] é necessário que exista [causa], porque existe [pressuposto]; e

(ii) a não ser que exista [causa] não existirá [efeito], porque existe [pressuposto] (Scheinkopf, 1999).

A Figura 2 apresenta os relacionamento descritos, empregando-se a notação utilizada por Scheinkopf (1999).

Os TP se valem de cinco ferramentas objetivas de aplicação (Kendall, 1998):

- Árvore da realidade atual (ARA): descreve uma realidade por meio de relações de causa e efeito, mostrando como os muitos efeitos indesejáveis se originam de poucas causas-raíz, normalmente condições de contorno físicas, conflitos não resolvidos ou pressupostos errôneos, que serão foco dos esforços de melhoria;

- Árvore da realidade futura (ARF): identifica a transformação necessária, projeta suas decorrências, prevê e previne novos problemas que podem decorrer da mudança;

- Diagrama de dispersão de nuvem (DDN): explicita os pressupostos de uma situação conflituosa, mostra por que o problema em foco não foi ainda resolvido, permite que se verifique que pressuposto errôneo gera o

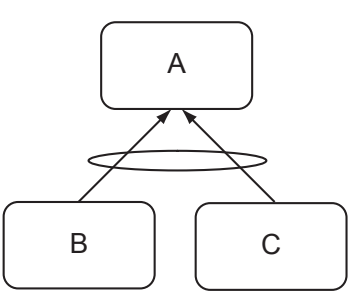

Se $B$ e $C$ existem, então A existe

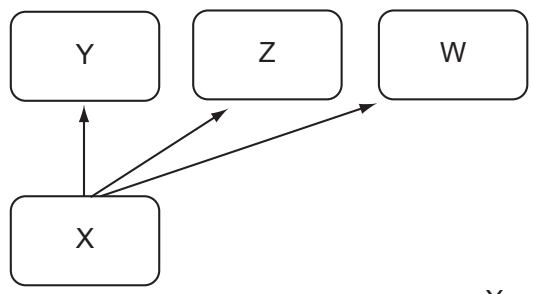

Se $X$ causa $Y$, então $Z$ e W existem
Figura 2. Representação das relações lógicas entre entes (Fonte: Scheinkopf, 1999). 
conflito e possibilita o surgimento de uma idéia nova e transformadora em relação à situação em análise;

- Árvore de pré-requisitos (APR): identifica os obstáculos que podem impedir que se atinja um objetivo, criando objetivos intermediários no caminho da solução definitiva e sugerindo um plano de ação para que se atinja a realidade projetada pela ARF; e

- Árvore de transição (AT): cria uma seqüência lógica e temporal de ações e transições dos estados que serão alcançados até o objetivo final, constituindo-se em um plano de ação, que pode ser detalhado até o nível que se queira.

A ARA define o que mudar, a ARF define para o que mudar, o DDN explicita o pressuposto errôneo que causa uma restrição, a AT define como causar a mudança e a APR descreve os obstáculos e a seqüência de transição da ARA à ARF. As ARA, ARF e AT usam a suficiência de causa, enquanto o DDN e a APR usam a condição necessária (Scheinkopf, 1999).

\subsection{A construção das cinco ferramentas objetivas de aplicação}

A descrição que segue é baseada em Scheinkopf (1999) e Dettmer (1997). O objetivo da ARA é representar lógica e claramente as relações efeito-causa-efeito válidas em uma situação complexa de interesse, geralmente multifacetada, polêmica e sem consenso.

Uma vez definida a situação de interesse, listam-se e conectam-se, em relações de precedência-consequiência, os efeitos indesejáveis. Aplicam-se as ressalvas legítimas, que refinam e depuram a ARA, conduzindo a uma forma final, focalizadora de uns poucos entes sem precedências, as causas-raiz.

Algumas causas são de difícil manejo. Mas algumas poucas causas-raiz são de manejo simples e originarão as ações de correção, as injeções, direcionadas pelo DDN. A construção do DDN exige uma redefinição do problema. Ao invés de partir do resultado indesejado, buscase uma incompatibilidade entre necessidades diferentes. O DDN explicita e desafia os pressupostos subjacentes à incompatibilidade. $\mathrm{O}$ pressuposto que não resistir ao DDN é considerado equivocado, recebendo uma injeção. Conhecidas as injeções e a ARA, constrói-se a ARF substituindo causa-raiz por injeções e projetando consequiências na realidade atual.

Uma das ressalvas legítimas que se aplica na ARF são os efeitos previsíveis, que apontam efeitos secundários das injeções, prevenindo eventuais novos efeitos indesejáveis. O conjunto das injeções, de suas exigências e dos efeitos indesejados gerados por elas dão origem à APR. A APR exige que se explicitem e se sequienciem os obstáculos que surgirão na implantação das injeções, estabelecendo objetivos intermediários. Identificados os obstáculos, pode-se concluir que não é necessário eliminar todos, bastando desviar por ações alternativas que também atingirão o objetivo intermediário visado. Uma sequiência de ações em uma APR é lida do seguinte modo: para atingir [objetivo intermediário posterior] é necessário [objetivo intermediário anterior] porque [obstáculo]. A APR ainda não é um plano de ação, mas uma sequiência de objetivos. O plano de ação é montado na AT. Para cada objetivo intermediário são especificadas ações e objetivos de controle. Enquanto este não for atingido aquela não é eficaz e o objetivo intermediário não é alcançado. Uma AT é lida: para atingir [objetivo intermediário posterior] é necessário atingir antes [objetivo intermediário anterior] e conduzir [ação\} até que [objetivo de controle] tenha ocorrido.

\section{Um caso de aplicação: o uso dos TP na gestão de materiaís de saúde}

A seguir se apresenta um caso de aplicação dos TP da TOC em uma situação de conflito na gestão de materiais de uso repetitivo em saúde pública em uma capital brasileira. A gestão é municipal e os materiais são distribuídos conforme a Figura 3. O método adotado foi a pesquisaação, pois a cada avanço na construção do conhecimento se ajustaram os procedimentos metodológicos, dinamizando a relação pesquisador-objeto.

Uma aplicação similar com materiais fabris é apresentada em Sellitto (2001). Os sistemas são iguais se classificados pelo tipo de relação e diferentes se classificados pelo tipo de elemento.

Os serviços de responsabilidade do munícipio, até 1997, eram restritos a menos de vinte pontos de atendimento, com uma limitada oferta de serviços. Era possível um gerenciamento por demanda: de tempos em tempos, os gestores de postos informavam os requisitos de materiais ao gestor logístico, que os comprava e entregava. Emergências eram tratadas por mobilizações extraordinárias ou por interações entre postos. Após 1997, municipalizados os serviços federais de saúde, os pontos geridos pelo município superaram a cem, aumentando a quantidade e a diversidade dos serviços. Aumentou-se

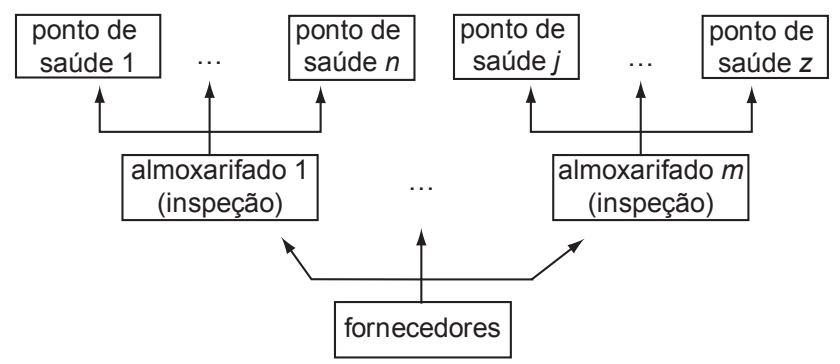

Figura 3. Distribuição e inspeção de materiais em saúde pública municipal. 
proporcionalmente o orçamento e manteve-se a técnica logística. Menos de dois anos depois o sistema logístico não era mais capaz de atender os gestores de postos de saúde nem na quantidade nem no prazo requerido. Para abordar este conflito adotou-se um método:

(i) construção da ARA;

(ii) construção do DDN, indicadores e injeções;

(iii) construção da ARF; e

(iv) construção das APR e AT.

Os efeitos indesejáveis levantados na situação de interesse foram usados na ARA da Figura 4:

(1) atraso na compra de reposição;

(2) excesso de alguns materiais e falta de outros;

(3) alto custo da logística de entrega;

(4) perdas por prazo de validade e por contaminação;

(5) uso inadequado de materiais;

(6) inventário alto;

(7) excesso de reclamações;

(8) relações impróprias entre as pessoas;

(9) verbas insuficientes;

(10) pouca transparência nos inventários;

(11) recusa dos gestores em ceder materiais entre postos; e

(12) pedidos de reposição superestimados.
O conetor A aponta o raciocínio circular. São itens independentes:

(13) pessoas não gostam de reclamações;

(14) clientes mal atendidos reclamam;

(15) pessoas se comportam conforme a medição de seus resultados;

(16) verbas são limitadas;

(17) falta de materiais compromete as medidas de resultado;

(18) pouca padronização de materiais; e

(19) rotas de distribuição aleatórias.

Os três primeiros são fatores comportamentais, o quarto e o quinto são condições de contorno. As causas-raiz controláveis são os itens (18) e (19).

O conflito e seus nexos causais estão representados no DDN da Figura 5. O conflito foi gerado pelo pressuposto errôneo de que a complexidade do sistema cresceria linearmente com as partes. Antes, as faltas eram pequenas em diversidade e volume, sendo supridas por sobras facilmente localizáveis. Com a nova demanda, maior e mais diversificada, as variáveis, os estados e principalmente as interações cresceram mais do que linearmente em relação às partes e ao orçamento. As faltas passaram a ser volumosas e diversificadas, sem sobras concentradas. Passaram a ser necessárias grandes operações de socorro, geralmente mal-sucedidas e geradoras de descrédito. O pressuposto é coerente com as causas-raiz da ARA: a pouca padroniza-

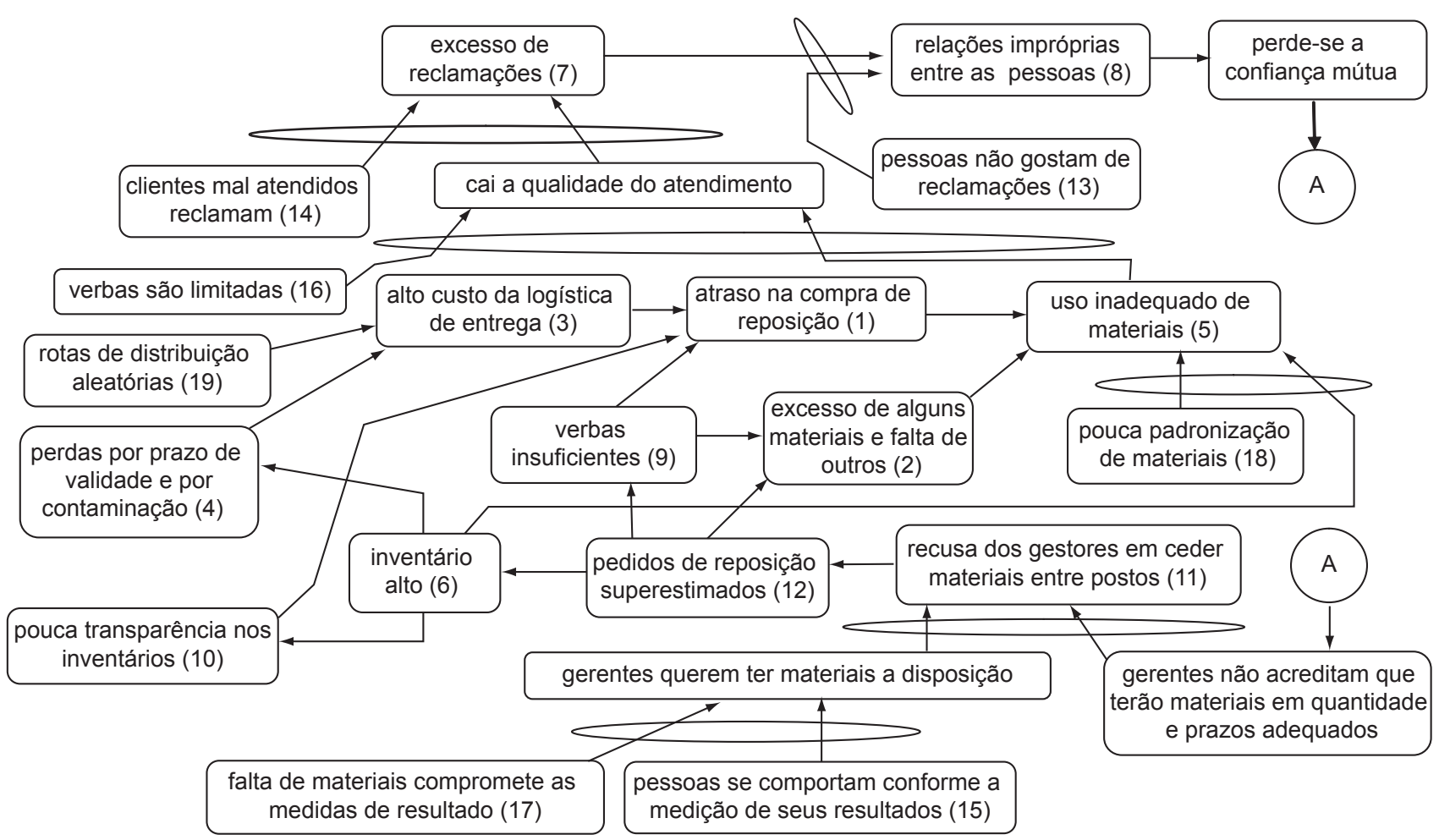

Figura 4. ARA da gestão e logística dos materiais de saúde. 
ção de materiais aumenta o número de emergências e o uso de rotas aleatórias gera baixa ocupação dos veículos. Ambos os fatores causam atrasos e forçam o uso de alternativas que reduzem ainda mais a padronização, em um enlace reforçador. O pressuposto errôneo gerou uma restrição invisível, a política de compra e entrega sob livre demanda, que gerou uma restrição física, a incapacidade da rede em atender aos requisitos de materiais.

Com o DDN especificam-se os indicadores do processo de melhoria. $\mathrm{O}$ indicador de resultado acompanha o objetivo operacional do gestor: número de unidades entregues no prazo. O inventário é representado pelo estoque médio nos postos. As despesas operacionais monitoram o objetivo de custo do gestor: gastos com veículos e mão-de-obra. $\mathrm{O}$ custo de aquisição dos materiais está mais relacionado ao resultado do que às despesas operacionais.

As injeções e seus impactos são projetados na ARF da Figura 6. As injeções exigem, para sua implementação, a superação de obstáculos que demarcam objetivos in-

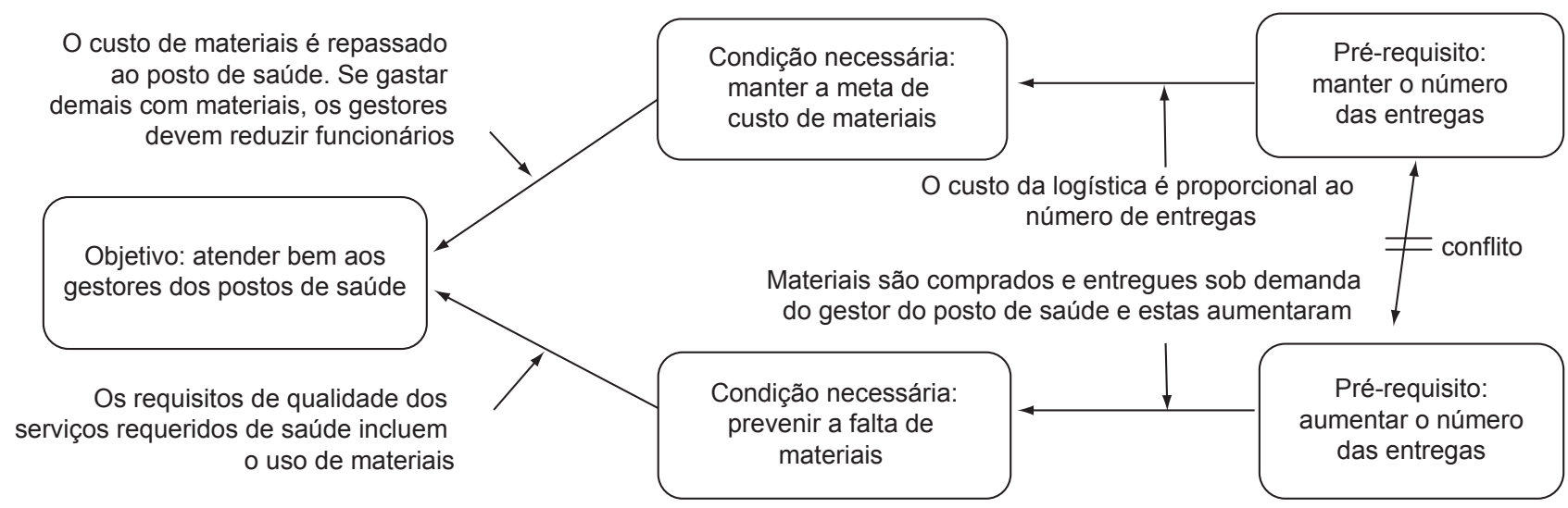

Figura 5. DDN da gestão de materiais.

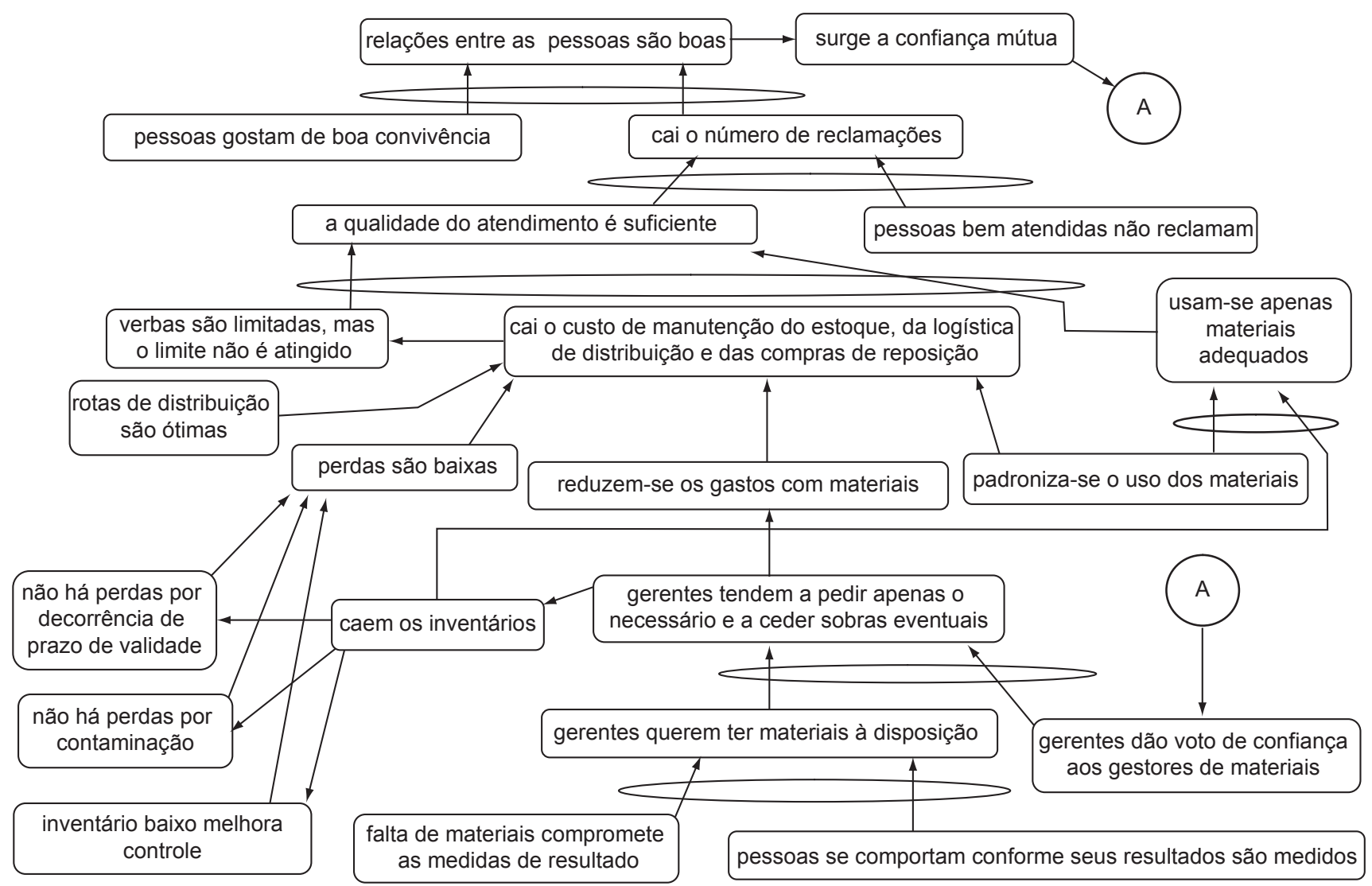

Figura 6. ARF da gestão e logística dos materiais de saúde. 
termediários. Para que se superem estes obstáculos são necessários planos de ação, compostos de ações propostas e objetivos de controle. Um objetivo intermediário anterior, uma ação proposta e um objetivo de controle formam um elo fechado que só se conclui quando a ação proposta atingir o objetivo de controle. O plano pode ser complementado por controles convencionais de tempo, recursos e alternativas contingenciais. A interligação entre objetivos intermediários e o plano de ação é representada pelo conjunto das Figuras 7 e 8, nas quais se têm as APR e AT do caso.

As injeções e suas decorrências são apresentadas a seguir:

- racionalização de procedimentos: cadastramento, padronização e registro do consumo de cento e dez itens, unificação do recebimento no almoxarifado central e organização da estocagem. Adoção da lógica FIFO (primeiro a entrar, primeiro a sair), contenedores exclusivos de dois acessos, nos quais a entrada de material se dá pela traseira e a retirada se dá pela dianteira, consumindo-se antes a unidade mais velha e prevenindo a mistura e a contaminação. Os itens mais pesados, mais volumosos e mais freqüentes ficaram abaixo e os itens mais leves ficaram acima, dispensando dispositivos de elevação, que danificam as embalagens. $\mathrm{O}$ cadastro mnemônico tornou o material inequívoco, permitindo visualizar irregularidades e prevenindo a reposição de itens existentes. A injeção exige o atingimento de objetivos intermediários:

(i) criar baias de armazenagem de fácil manejo, identificação e acesso;

(ii) identificar um local que cumpra os requisitos para sediar o almoxarifado; e

(iii) especificar os materiais e suas quantidades e criar códigos mnemônicos que os expressem; e

- otimização das rotas e unificação das entregas: a entrega se dá em uma única rota, periódica e calculada para aumentar a carga do veículo, ao invés de se atenderem às demandas de modo aleatório, com maior quilometragem e menor ocupação dos veículos. A injeção exige o atingimento de objetivos intermediários:

(i) fazer previsão do uso com base no histórico das quantidades consumidas;

(ii) padronizar os materiais disponíveis e limitar o uso aos materiais padronizados; $\mathrm{e}$

(iii) conscientizar usuários de materiais que o mau uso dos recursos prejudica o cumprimento da missão.

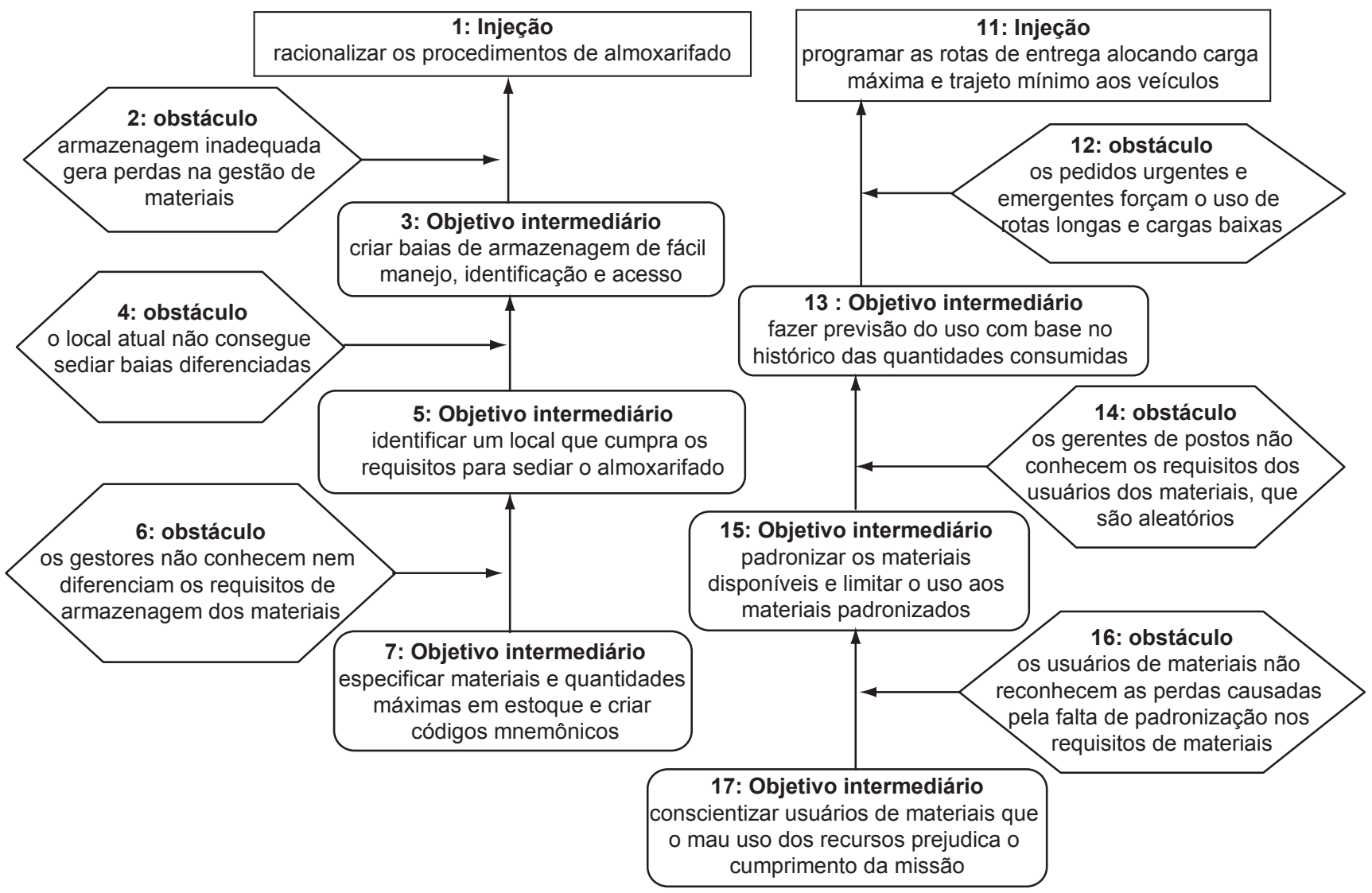

Figura 7. A árvore dos pré-requisitos. 
3: Objetivo intermediário

criar baias de armazenagem de fácil manejo, identificação e acesso
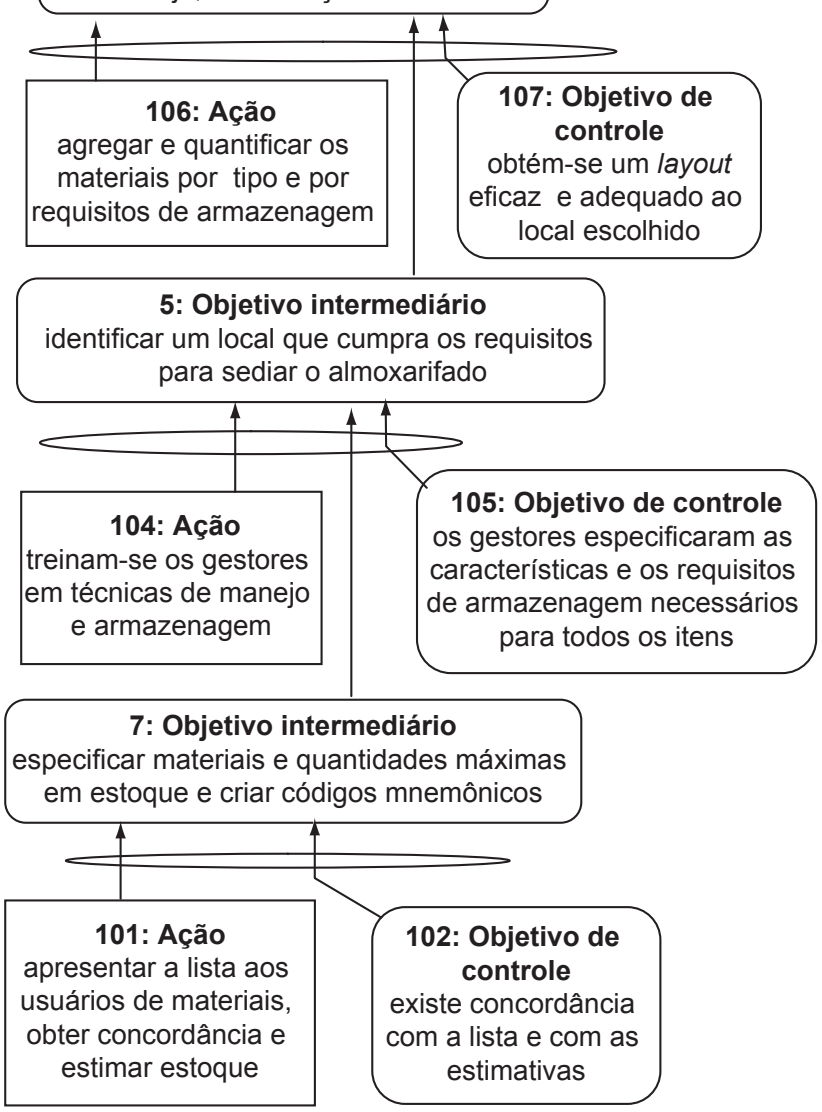

Figura 8. A árvore de transição.

\section{Discussão}

O tempo de planejamento do projeto foi de nove meses. Procurou-se ser o mais fiel possível ao método da TOC ao planejar a intervenção e ao plano ao executá-la. No entanto, houve alternâncias em procedimentos devidas ao longo prazo do projeto e à incerteza percebida no início do trabalho, que motivaram a adoção da pesquisaação como perspectiva metodológica.

Inicia-se discutindo os resultados específicos do caso. A primeira injeção trouxe como benefícios a racionalização das tarefas de inspeção e armazenagem, concentradas em um pavilhão industrial, com áreas para carga, descarga e manuseio, visibilidade e acesso aos itens, eliminando as perdas por contaminação, dano na embalagem, deterioração e perda de validade. Os códigos mnemônicos facilitaram o acesso para carga e a contagem e vistorias para reposição, reduzindo os erros de entrega e de compra. Na segunda injeção, os profissionais de saúde padronizaram cento e dez itens, cujos consumos passaram a ser controlados em um sistema de informações. Itens excepcionais, como campanhas e emergências, con-

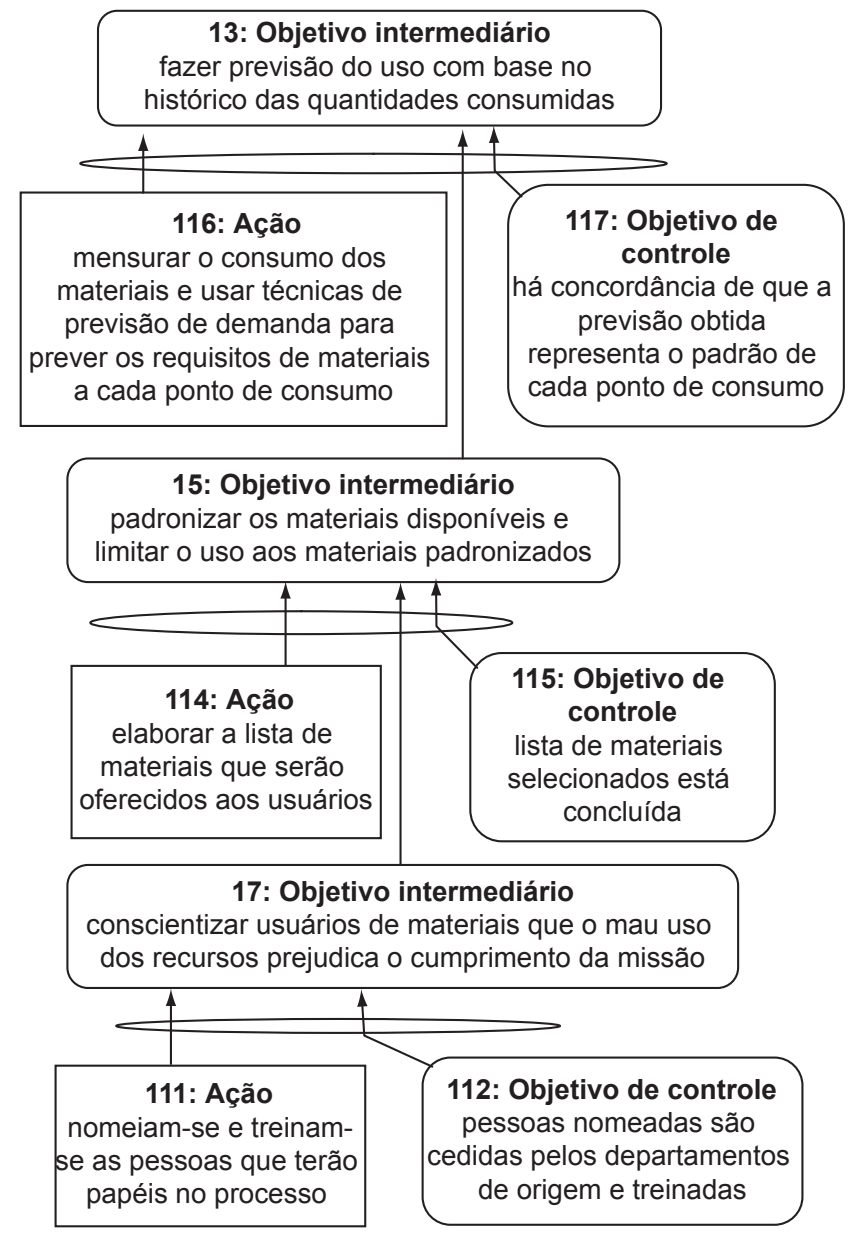

13: Objetivo intermediário

fazer previsão do uso com base no

histórico das quantidades consumidas

116: Ação

mensurar o consumo dos

materiais e usar técnicas de

ver os requisitos de materiais

padronizar os materiais disponíveis $e$

limitar o uso aos materiais padronizados

17: Objetivo intermediário

conscientizar usuários de materiais que o mau uso dos recursos prejudica o cumprimento da missão previsão de consumo baseada na média mensal ajustada por sazonalidades, permitindo uma rota de entregas periódicas padronizadas. A carga foi composta pela previsão menos o estoque apurado nos pequenos depósitos junto aos pontos de consumo. Devido às duas injeções, em seis meses, todos os indicadores registraram melhorias. O resultado cresceu $60 \%$, passando-se de cerca de 4,5 para 7,2 milhões de unidades equivalentes entregues por mês. $\mathrm{O}$ estoque médio se reduziu em cerca de $15 \%$, passando de 20 para 17 milhões de unidades equivalentes. $\mathrm{O}$ giro de estoque subiu de cerca de duas e meia vezes ao ano para cerca de cinco vezes ao ano. As despesas com transportes se mantiveram constantes, apesar do aumento em $60 \%$ das entregas e a mão-de-obra requerida caiu de vinte e cinco para vinte e um colaboradores. As reclamações dos gestores de postos de saúde, antes freqüentes, foram zeradas. As faltas de materiais atingiram níveis insignificantes.

Quanto ao método de trabalho, apesar de ter sido na ARA que as injeções foram identificadas, o verdadeiro fio condutor da intervenção foi o DDN. Caso o pressu- 
posto da não-linearidade da escala de produção não tivesse sido explicitado, possivelmente as injeções não teriam atingindo a verdadeira origem do conflito, a maior complexidade das interações com os pontos de consumo. A ARF trouxe menor contribuição para o entendimento da situação e apenas confirmou o teor das injeções, não aportando nenhum elemento novo. O conjunto das APR e AT foi útil para organizar e seqüenciar as ações em grandes blocos, mas foi insuficiente para o gerenciamento da rotina do projeto. Foi necessário o uso do método do caminho crítico $(C P M)$ e dos diagramas PERT. Remete-se para a continuidade o estudo da ligação das APR e AT com esta ferramenta.

\subsection{Comparação entre o método sistêmi- co e o método da TOC}

$\mathrm{Na}$ Tabela 2 comparam-se elementos do método da TOC com os níveis do método sistêmico.

Aos eventos tangíveis do método sistêmico correspon-

Tabela 2. Comparação entre os níveis do pensamento sistêmico e elementos da TOC.

\begin{tabular}{|c|c|c|}
\hline $\begin{array}{c}\text { Níveis do } \\
\text { pensamento } \\
\text { sistêmico } \\
\end{array}$ & $\begin{array}{c}\text { Elementos dos } \\
\text { processos de } \\
\text { pensamento } \\
\end{array}$ & $\begin{array}{c}\text { Tipo de } \\
\text { semelhança }\end{array}$ \\
\hline Eventos tangíveis & Efeitos indesejáveis & Forte \\
\hline $\begin{array}{l}\text { Padrões de } \\
\text { comportamento }\end{array}$ & $\begin{array}{l}\text { Quinto passo do método de } \\
\text { focalização de restrições: } \\
\text { inércia }\end{array}$ & Fraca \\
\hline $\begin{array}{l}\text { Estrutura } \\
\text { sistêmica }\end{array}$ & $\begin{array}{l}\text { Relações de causalidade da } \\
\text { ARA }\end{array}$ & Forte \\
\hline Modelos mentais & $\begin{array}{l}\text { Pressupostos subjacentes às } \\
\text { relações de causalidade }\end{array}$ & Forte \\
\hline
\end{tabular}

dem os efeitos indesejáveis da TOC, apontados a partir das percepções de agentes e verificáveis na realidade sensível. Também se observa que não existe nos $T P$ uma correspondência aos padrões de comportamento, pois a TOC não considera formalmente efeitos no longo termo, o que torna sua análise estática, em oposição à análise sistêmica, que é dinâmica. A TOC considera aspectos temporais apenas no alerta que faz no quinto passo do método de gerenciamento de restrições. Às estruturas sistêmicas correspondem, na $T O C$, as relações de causalidade da ARA. O processo de construção das duas é semelhante, chegando a estruturas equivalentes, se bem que com outra simbologia. Os modelos mentais do método sistêmico guardam relação com os pressupostos da TOC. Enquanto os modelos mentais consideram crenças, valores e convicções dos decisores, a explicitação dos pressupostos exige a aplicação das ressalvas legítimas. A explicitação dos pressupostos explora o nexo causal que une causa e efeito e a aplicação das ressalvas legítimas permite que os níveis mais superficiais se tranformem em elementos da ARA e os níveis mais profundos se tornem os novos pressupostos, tal como no passo 7 do método sistêmico. Como os âmbitos típicos de aplicação parecem guardar similaridade, entende-se que a semelhança entre os tópicos é forte.

Na Tabela 3 comparam-se de modo sinótico o método sistêmico e o método da TOC.

Nas duas primeiras linhas se observa que ambos os métodos iniciam delimitando o campo de ação por meio de um tema e de um conjunto de circunstâncias. No entanto, entende-se que a relação entre o segundo passo do método sistêmico e o levantamento dos efeitos indesejáveis é apenas média, pois o método sistêmico se preocupa também com o aspecto temporal, enquanto que a

Tabela 3. Comparação entre os métodos sistêmicos e da TOC.

\begin{tabular}{llc}
\hline \multicolumn{1}{c}{ Método sistêmico } & \multicolumn{1}{c}{ Método da TOC } & Semelhança \\
\hline definir a situação complexa de interesse & definir o foco de trabalho & forte \\
apresentar a história por meio de eventos & apontar os efeitos indesejáveis & média \\
identificar os fatores-chave & testar os efeitos indesejáveis e fazer o DDN & forte \\
levantar o comportamento histórico & testar o efeito quanto à inércia & fraca \\
identificar as relações de influência e as relações & construção da ARA & forte \\
causais & aplicar as ressalvas legítimas & forte \\
$\begin{array}{l}\text { identificar os modelos mentais } \\
\text { incorporar os modelos mentais na estrutura }\end{array}$ & aplicar as ressalvas legítimas & média \\
sistêmica & não existe formalmente, mas pode-se partir de uma & fraca \\
se possível, aplicar um arquétipo & ARA existente & inexistente \\
modelar em computador & não existe correspondente & fraca \\
tentar alternativas no simulador & as alternativas são testadas na ARF & inexistente \\
não existe correspondente & APR e AT & \\
\hline
\end{tabular}


TOC parece se preocupar mais se existe ou não o fator. Na seqüência, a investigação dos fatores-chave do método sistêmico encontra correspondência na construção do DDN. No método sistêmico os fatores-chave são identificados, ao passo que no DDN, os pressupostos, além de explicitados, são julgados. No próximo passo, o método sistêmico investiga e considera relevante o padrão de comportamento temporal no estabelecimento das relações causa-efeito, incentivando a construção de gráficos das variáveis, enquanto que o método da TOC apenas verifica se os já identificados e julgados pressupostos são resíduos inerciais. Como as diferenças são grandes, entende-se que a correspondência é fraca.

Os quatro passos seguintes são analisados em conjunto. O método sistêmico identifica os fatores de influência e por conseqüência as relações causa-efeito, construindo uma estrutura inicial capaz de descrever a situação complexa em análise. À medida que os modelos mentais subjacentes às relações de influência vão sendo entendidos, se cabível, vão se tornando elementos da estrutura, que vai se refinando e ficando mais próxima à realidade, até que seja suficiente para os objetivos da análise. Se possível, deve ser tentada a adaptação de um arquétipo existente para a nova situação. Já o método da TOC relaciona os efeitos indesejáveis de acordo com relações lógicas de conseqüência e procedência. Neste ponto se tem uma configuração preliminar da ARA. Para se certificar da validade das relações estabelecidas, o método requer que se explicitem os pressupostos subjacentes às relações, sob a forma de nexos causais. A explicitação destes pressupostos é relevante pois, ao se montar a ARA inicial, alguns pressupostos podem ter sido admitidos automaticamente, sem que sua validade tenha sido verificada. Neste momento se aplicam as ressalvas legítimas, que podem gerar novos entes, incorporados à ARA definitiva. Tanto em um como em outro método, neste ponto se tem a estrutura definitiva sobre a qual se operará até o final do processo.

A partir deste ponto os métodos diferem totalmente. Enquanto o método sistêmico trata de modelar e simular a estrutura obtida em computador, escolhendo o cenário mais conveniente, a TOC constrói cenários estáticos por meio da ARF. A partir do cenário escolhido, oferece uma alternativa de gerenciamento por um plano de ação: as APR e AT. Estas duas árvores são instrumentos de controle de ações de curto prazo, com pontos de controle e de redirecionamento de ações. A base para esta diferença parece ser a importância que o método sistêmico dá aos efeitos de longo termo, ao contrário da TOC. Talvez Goldratt creia que a mudança em cenários e pressupostos ocorra em uma velocidade maior do que o processo capta. Esta opinião se baseia nas observações que faz Goldratt (1996) sobre a velocidade em que ocorrem as mudanças na corrida pela competitividade nos negócios.

Também é possível comparar brevemente o método da TOC com o resumo da metodologia soft do pensamento sistêmico apresentada em Checkland e Scholes (1999). Os autores entendem, sumariamente, que:

(i) o pensamento sistêmico considera a idéia de um todo (holon) cujas propriedades não são relacionadas às suas partes, mas unicamente ao todo;

(ii) pensar sistemicamente significa construir todos abstratos, os modelos sistêmicos, que devem ser comparados ao mundo real para análise, aprendizado e ação modificadora da realidade; $\mathrm{e}$

(iii) na tradição soft, o processo de investigação, mais do que o objeto investigado, é que é sistêmico.

O processo sistêmico de investigação, segundo os autores, usaria modelos abstratos de sistemas, dos quais os modelos exatos ou concretos são apenas um tipo. $\mathrm{O}$ processo da TOC também propõe um modelo abstrato de aprendizado, a ARA, construída interativamente, que é confrontado com o mundo real pelo DDN. Ao fim, as ações modificadoras da realidade sugeridas pelo modelo abstrato são guiadas pelas ARF, APR e AT.

Finaliza-se explorando o caráter sistêmico da análise através da Figura 9. Nesta figura o caso, é representado como um sistema de controle monomalha realimentado a variáveis discretas. A variável de controle é a previsão de consumo, a variável de resposta é o consumo real e a variável interna ou manipulada é a quantidade a ser comprada como reposição.

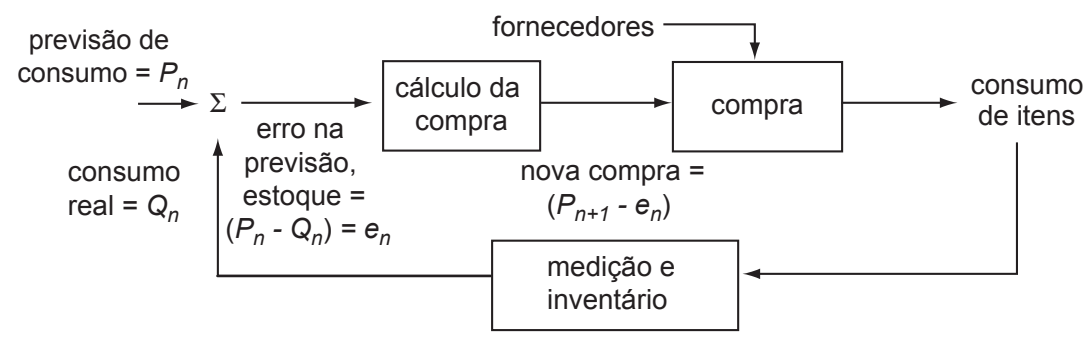

Figura 9. Representação do sistema de gestão de materiais analisado pela TOC como monomalha fechada. 


\section{Conclusões}

O objetivo deste trabalho foi discutir o uso dos processos de pensamento da TOC como alternativa para o planejamento de uma intervenção organizacional com base no pensamento sistêmico. A metodologia adotada foi a revisão de conceitos, a referência a um dos métodos sistêmicos existentes na literatura, a descrição teórica e um exemplo de aplicação do método da $T O C$, a comparação entre os dois métodos e a conclusão.

As técnicas usadas no caso são conhecidas na fabricação: padronização de materiais, previsão de consumo e unificação de rotas. Foi possível a transferência destas técnicas para o caso em estudo pela igual classificação sistêmica dada a ambas as situações pelo critério relacional.

Talvez a contribuição deste trabalho seja metodológica. Na revisão conceitual, observou-se que os métodos de intervenção possuem três etapas: leitura da situação, diagnóstico e plano de trabalho. No caso de aplicação do método da TOC cerca de $90 \%$ do tempo foi utilizado na leitura e no diagnóstico. A leitura é suficientemente abordada por ambos os métodos, que parecem chegar a resultados equivalentes. O diagnóstico também é bastante enfocado pelos métodos, mas estes não chegam a resultados equivalentes: a TOC identifica e julga pressupostos, ao passo que o método sistêmico identifica arquétipos, não os julgando. Já o plano de trabalho conduz a resultados bastante diferentes. Enquanto a TOC chega a um plano de ação para a intervenção, o método sistêmico testa alternativas em simuladores. Por gerar um plano imediato e por considerar apenas o curto termo, a TOC parece ser mais indicada para a análise de situações estáticas. Já o método sistêmico parece tratar melhor situações dinâmicas, mas não oferece uma alternativa de teste rápido e não se preocupou em unificar o gerenciamento do projeto.

À $T O C$ falta uma abordagem quantitativa e principalmente probabilística para as variáveis. Os valores de fluxo e estoque seguem distribuições de probabilidade desconsideradas nas obras referenciadas sobre a TOC, que parece se preocupar mais com macroindicadores, como os apurados no estudo de caso, negligenciando os graus de liberdade e as distribuições de probabilidade das gran- dezas medidas. O próprio conceito de restrição é probabilístico. Ao invés de classificar um único ente como restrição, um procedimento deveria calcular as probabilidades que cada ente possível tem de ser a restrição investigada, o que não foi encontrado na bibliografia referenciada.

Talvez uma nova definição para restrição deva ser proposta, capaz de abranger ao menos duas situações que não são suficientemente explicadas pela definição atual:

(i) em sistemas de trabalho de alta flexibilidade e alta capacidade de adaptação, como em trabalho intelectual ou puramente manual, uma restrição nascente é imediatamente compensada pelo rearranjo de recursos eventualmente ociosos, não chegando a assumir a condição restritiva; e

(ii) em sistemas em que a restrição se desloca com mais velocidade do que o sistema pode captar, jamais se terá uma restrição localizada e gerenciada.

Conclui-se que os processos de pensamento da TOC parecem ser úteis como alternativa de planejamento de intervenções de curto termo ou estáticas, enquanto que o método sistêmico parece ser útil em situações de longo termo ou de comportamento dinâmico mais complexo.

Como sugestão para a continuidade dos trabalhos, aponta-se a determinação analítica da complexidade do caso e a interligação de instrumentos automatizados de gerenciamento de projetos com ao menos um software de simulação e com as APR e AT. Para o método da TOC se aponta a necessidade de não mais se negligenciarem os aspectos probabilísticos das variáveis e das restrições, se possível propondo uma redefinição do conceito de restrição que expliquem as objeções apontadas.

\section{Reconhecimentos}

Deseja-se reconhecer o mérito das sugestões e contribuições do professor PhD Paulo Fernando Barcellos, e das discussões com o MSc doutorando Aurélio Andrade, ambos do PPGEP-UFRGS, e o incentivo ao trabalho em bases metodológicas recebido da Intercorp Consultoria Empresarial, importantes para a concretização deste trabalho. Também se deseja agradecer as sugestões de melhorias e palavras de estímulo recebidas dos referees anônimos. 
ANDRADE, A. Pensamento Sistêmico: Um Roteiro Básico para Perceber as Estruturas da Realidade Organizacional. REAd - Revista Eletrônica de Administração. Disponível em: <http://www.cesup.ufrgs.br/TPGA/read/ read05/artigo/andrade.htm>. TPGA/UFRGS, $n^{\circ}$ 4. 04/97, 1997. Acesso em agosto de 2003.

ANDRADE, A.; KASPER, H.: Pensamento sistêmico, 1997. Disponível em: <http://planeta.terra.com.br/negocios/processos2002/pensamento_sistemico.htm>. 2002, Acesso em agosto de 2003.

BERTALANFFY, L. Teoria geral dos sistemas. Petrópolis: Vozes, 1977.

CHECKLAND, P.; SCHOLES, J. Systems thinking, systems practice. Chichester, West Sussex: John Wiley \& Sons. 1998

CHECKLAND, P.; SCHOLES, J. Soft systems methodology in action. Chichester, West Sussex: John Wiley \& Sons, 1999.

D'AZZO, J.; HOUPIS, C. Linear control system analysis and design: conventional and modern. New York: McGraw-Hill, 1995.

DESCARTES, R. O discurso do método. S. Paulo: Martins Fontes, 1996.

DETTMER, W. Goldratt's theory of constraints. Milwauke: ASQ, 1997.

ENSSLIN, L; MONTIBELLER, G.; NORONHA, S. Apoio à decisão. Florianópolis: Insular, 2001.

FORRESTER, J. Priciples of systems. Cambridge, MA: Writgh-Allen Press, 1968.

FREGOSI, A; FEINSTEIN, J.; CALDEIRA, L. Enfoque classico da teoria de controle. R. Janeiro: Campus, 1980.

GOLDRATT, E. Computerized shop floor scheduling, International Journal of Production Research, v. 26, n. 3, 1988 .

GOLDRATT, E. Theory of constraints, Great Barrington: North River Press, 1990.

GOLDRATT, E. A síndrome do palheiro. S. Paulo: Educator, 1996.

GOODMAN, M. Pensamento Sistêmico in A quinta disciplina: caderno de campo. R. Janeiro: Qualitymark, 1996.

JACKSON, M. Systemic methods in management sci- ences. New York: Plenum Press, 1993.

KENDALL, G. Securing the future: strategies for exponential growth using the theory of constraints, Boca Raton: St. Lucia Press. 1998.

KLIR, G. Facets of systems sciences. New York: Plenum Press, 1991.

LAKATOS, E; MARCONI, M. Fundamentos de metodologia científica. S. Paulo: Atlas, 1991.

NOREEN, E.; SMITH, D; MACKEY, J. A teoria das restrições e suas implicações na contabilidade gerencial. S. Paulo: Educator, 1996.

OSSIMITZ, G. The development of systems thinking skills using system dynamics modeling tools, 1997. Disponível em <http://www.uni-klu.ac.at/users/gossimit/ sdyn/gdm_eng.htm>. Acesso em fev/2004.

PHILLIPS, C.; HARBOR, R. Sistemas de controle e realimentação. S. Paulo: Makron Books, 1997.

PIDD, M. Modelagem empresarial. Porto Alegre: Bookman, 1998.

RODRIGUES, L. Apresentação e análise critica da Tecnologia da Produção Otimizada (Optimized Production Technology - OPT) e da Teoria das Restrições (Theory Of Constraints - TOC). Anais, XIV Enanpad, Florianópolis: Anpad, 1990

SELLITTO, M. Sistema de produção sincronizado: uma aplicação em processos produtivos de propriedade contínuos segundo a teoria das restrições. dissertação de mestrado. PPGEP UFRGS. Porto Alegre: 1999.

SELLITTO, M. Aplicando um modelo de intervenção para redução de atrasos em fabricação seriada, com base na teoria das restrições. Revista Produto \& Produção, v. 5, n. 1, p. 45-52, fev/2001.

SENGE, P. A Quinta Disciplina. S. Paulo: Best Seller, 1990.

SHEINKOPF, L. Thinking for a change: putting the TOC thinking process to use. Boca Raton: St. Lucia Press, 1999.

SOUZA FILHO, D. Iniciação à história da filosofia. R. Janeiro: Jorge Zahar, 2000.

WIENDAHL, H. Betriebs-Organisation für Ingenieure. s.l.: Carl Hansen Verlag, 1989. 


\section{TOC THINKING PROCESS AS A SYSTEMIC ALTERNATIVE FOR ORGANIZATIONAL ANALYSIS: AN APPLICATION IN PUBLIC HEALTH}

Abstract

This paper discusses the use of the TOC (theory of constraints) thinking process as an alternative to systemic organizational analyses. We begin with a conceptual review of systemic thought, a reference to one of the various methods available in the literature, and a review of the basics and main concepts of the TOC. This is followed by the discussion of a case study, in which the TOC method was applied in a public health service organization, and a comparison of the TOC method and the systemic method. The conclusion of this paper discusses the relation between the methods and systemic situations, outlining the kinds of situation in which each method seems to work best by producing acceptable organizational results.

Keywords: systemic thinking, theory of constraints, thinking process of the theory of constraints, organizational intervention planning. 